\title{
Fine-grained structure formation in LiF single crystals during compression at intermediate temperature
}

\author{
O.S. Sitdikov ${ }^{1,2, \dagger}$ \\ ${ }^{1}$ Institute for Metals Superplasticity Problems RAS, Khalturin Str. 39, 450001 Ufa \\ ${ }^{2}$ Bashkortostan State University, Validy Str. 32, 450076 Ufa \\ †sitdikov.oleg@anrb.ru
}

\section{Формирование мелкозернистой структуры в монокристаллах LiF в процессе теплой деформации сжатием \\ Ситдиков О.Ш. ${ }^{1,2}$}

\author{
${ }^{1}$ Институт проблем сверхпластичности металлов РАН, ул. Халтурина 39, 450001 г. Уфа \\ ${ }^{2}$ Башкирский государственный университет, ул. Валиди, 32, 450076 г. Уфа
}

\begin{abstract}
The microstructural evolution and a character of dislocation glide have been examined in $<100>$ oriented LiF single crystals at $673 \mathrm{~K}$ by means of optical microscopy and X-ray analysis. It has been shown that the continuous dynamic recrystallization (CDRX) results in the formation of recrystallized grains. Localization of dislocation glide plays an important role in CDRX providing the formation of separate band-like subgrains after small strain. Longitudinal boundaries of such bands exhibit low migrating ability that prevents collision and following mutual annihilation of subboundaries of opposite signs. As a result, highly stable arrays of low-angle boundaries are formed. Further plastic deformation, leading to continuous increase in misorientation of subboundaries and their eventual conversion into high angle ones, results in the formation of recrystallized grains.
\end{abstract}

Keywords: LiF single crystal, localization of plastic deformation, fine-grained structure.

\section{Introduction}

The main mechanism of grain boundary formation during plastic deformation in materials with high stackingfault energy (SFE) is continuous conversion of low angle boundaries into high angle ones [1,2] through CDRX. This type of structure evolution has often been observed in minerals [3] and metals [4-6]. However, although the experimental observations of structural evolution in these works were quite detailed, some important aspects of CDRX remain unclear. It is known [1], that the existence
Методами оптической микроскопии и рентгеноструктурного анализа исследуются эволюция микроструктуры и характер дислокационного скольжения при температуре 673 К в монокристаллах LiF, ориентированных вдоль направления $<100>$. Показано, что непрерывная динамическая рекристаллизация (НДР) ведет к формированию рекристаллизованных зерен. Локализация дислокационного скольжения играет важную роль в НДР, обеспечивая развитие полосовых субструктур при относительно небольших степенях деформации. Продольные границы таких полос демонстрируют низкую способность к миграции во время деформации, что препятствует слиянию и последующей аннигиляции субграниц, образованных дислокациями противоположного знака, и способствует образованию стабильных сеток малоугловых границ. Последующая пластическая деформация, сопровождающаяся непрерывным увеличением разориентировки субграниц и их трансформацией в высокоугловые границы, приводит к формированию рекристаллизованной структуры.

Ключевые слова: монокристаллы LiF, локализация деформации, мелкозернистая структура

of a stable network of subboundaries is a main condition for CDRX occurrence. The interaction between sliding dislocations and a stable low-angle boundary can result in growth of its misorientation and gradual conversion into a high-angle boundary. It was assumed [1] that the stability of subgrain structure in multiphase materials was mainly caused by pinning of boundaries by second-phase particles. However, this assumption is unable to explain CDRX occurrence in single-phase materials, such as $\mathrm{NaCl}$ [3] or pure $\mathrm{Al}$ [4]. From this point of view it is interesting to 
consider the microstructural evolution in a pure high SFE material in details. For this purpose the main aspects of the microstructural development in $<100\rangle$-oriented LiF single crystals are studied in the present work.

\section{Experimental Procedure}

LiF single crystals were deformed under applied stress parallel to $\langle 100\rangle$. Samples for tests had the shape of a rectangular parallelepiped being normally $8 \mathrm{~mm}$ long and about $6 \mathrm{~mm}$ thick. The samples were cleaved along (100) plane, annealed at $873 \mathrm{~K}$ for 5 hours and cooled in the furnace. Compression tests were conducted using a testing machine "Schenck RMS-1000M" at an initial strain rate of $4.2 \times 10^{-3} \mathrm{~s}^{-1}$, at a temperature of $673 \mathrm{~K}\left(\approx 0.6 \mathrm{~T}_{\mathrm{m}}\right.$, where $\mathrm{T}_{\mathrm{m}}$ is a melting point). After testing, the samples were rapidly unloaded and cooled in air. For microstructural examination the samples were cleaved, polished and etched in 30\% aqueous solution of fluoboric acid. The surface relief and the microstructure were studied with the optical microscopes "Neophot-32" and Nikon L-150. The X-ray structural analysis was performed by a photo method using the X-ray device URS-2.0.

\section{Results}

3.1 Mechanical testing. A true stress-strain curve of the LiF single crystal for $\mathrm{T}=673 \mathrm{~K}$ and $\varepsilon=4.2 \times 10^{-3} \mathrm{~s}^{-1}$ is shown in Fig. 1. It is seen that four stages of work hardening [7] can be denoted on this curve at $\varepsilon \leq 0.5$. In comparison with the number of other ionic and metallic crystals [8] the transition regions $\left(\varepsilon_{\mathrm{I}-\mathrm{II}}\right.$ and $\left.\varepsilon_{\mathrm{IIIIII}}\right)$ between stages with constant hardening rates were found to be more extended and their duration was comparable with that of "main" work - hardening stages $\left(\varepsilon_{\mathrm{I}}\right.$, $\varepsilon_{\mathrm{II}}$ and $\left.\varepsilon_{\mathrm{III}}\right)$. The great majority of the deformation proceeded in stage IV. The duration of this stage exceeds the duration of other stages of I, II and III. The stages revealed are distinguished by the work-hardening rate, $\Theta=1 / 4(\mathrm{~d} \sigma / \mathrm{d} \varepsilon)$ [7]. The minimal $\Theta$ of $3.9 \mathrm{MPa}$ is observed in stage III. At the same time there is a relative extensive material hardening in stages II and IV (with $\Theta \approx 33.6$ and $31.3 \mathrm{MPa}$, respectively).

Thus the flow stresses in LiF single crystals at $673 \mathrm{~K}$ increase monotonically with strain. At $\varepsilon>0.5$, the flow stresses trend to saturate at $\sigma \rightarrow 60 \mathrm{MPa}$. However, no steady state of plastic flow was reached even when $\varepsilon \approx 0.6-0.7$. Note that a similar mechanical behavior was earlier reported for some $<100>$-oriented simple ionic crystals at strain rates $10^{-5}-10^{-2} \mathrm{~s}^{-1}$ and at homological temperatures of about 0.4 $0.6 \mathrm{~T}_{\mathrm{m}}[7,9-11]$. It is in the contrast to the higher temperatures of $\mathrm{T}>0.7 \mathrm{~T}_{\mathrm{m}}$, when the flow stresses under conditions of active loading [10] or strain rates in creep tests $[9,11]$ were essentially constant over a large range of strains. For $\langle 100\rangle$-oriented LiF single crystals the transition from curves exhibited four stages of plastic flow to those exhibited the stage III with $\Theta \rightarrow 0$ in a wide strain interval takes place with increasing temperature from 673 to $873 \mathrm{~K}[7,10]$.

3.2. Surface observations. The metallographic surface features were found to be dependent on strain. At the end of stage I, two operating orthogonal $\{110\}<110>$ slip systems were observed (Fig. 2a). The long straight lines of both systems intersected the body of a single crystal. Their distribution was quite homogeneous. Each slip system was

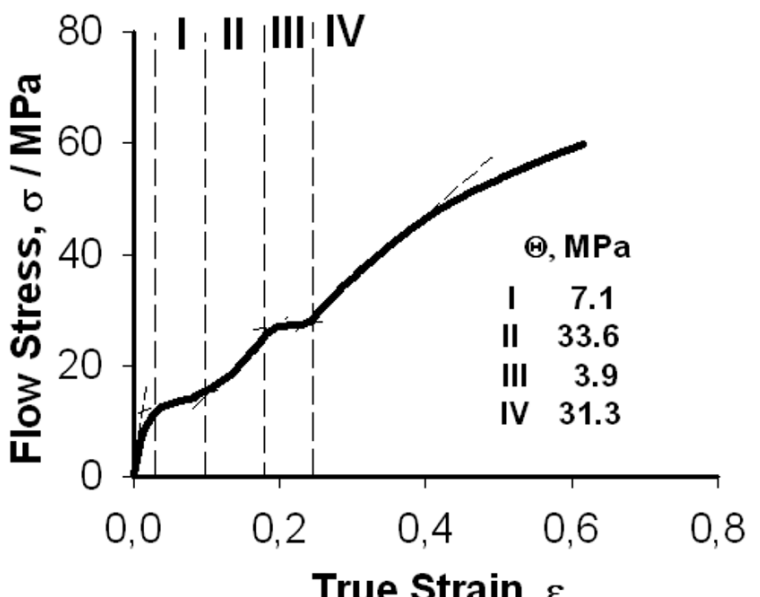

Fig. 1. True stress-strain curve and values of work-hardening rate $(\Theta)$ in $\mathrm{LiF}$ single crystals.
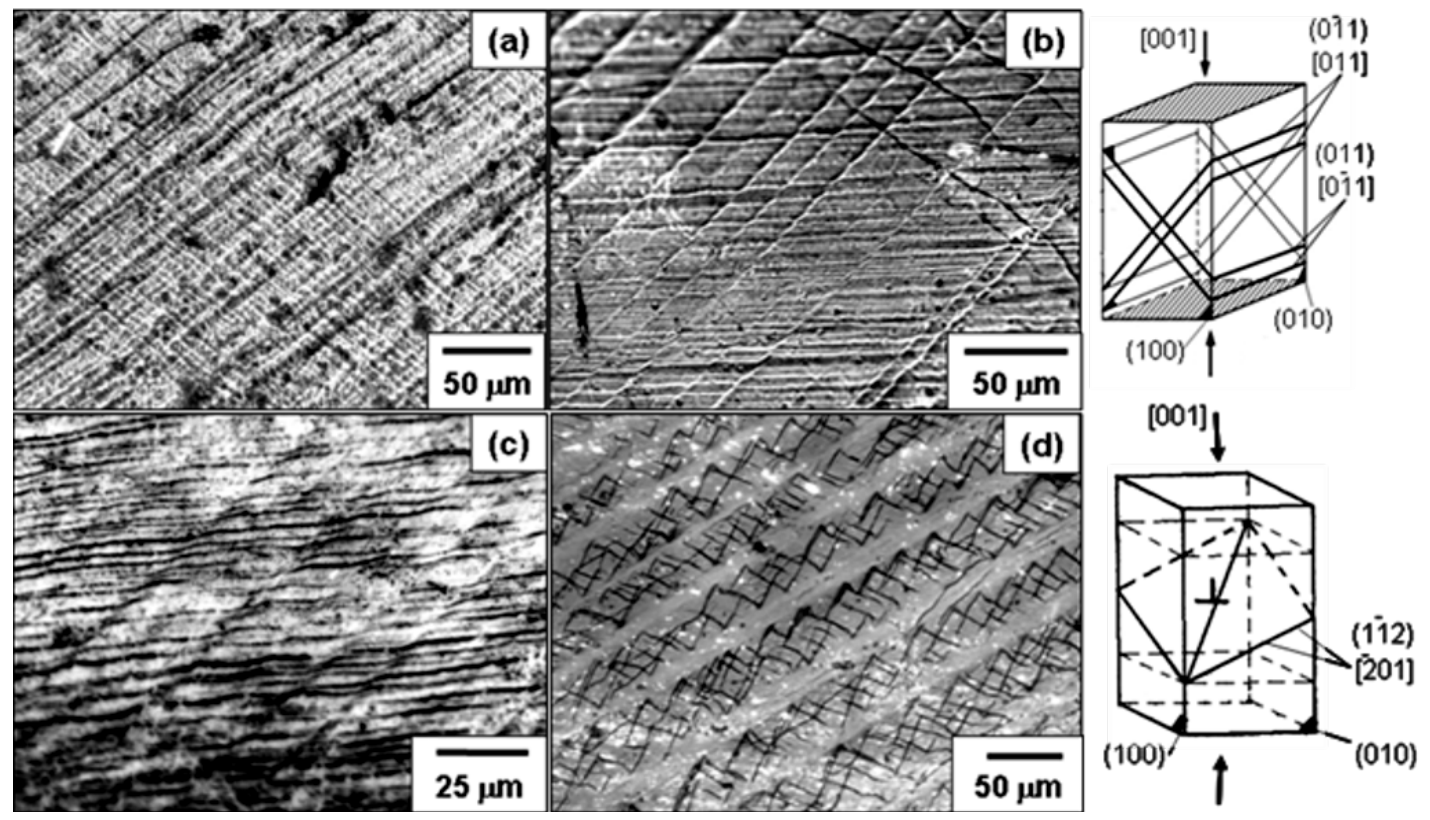

Fig. 2 Deformation relief of $\mathrm{LiF}$ deformed at $\mathrm{T}=673 \mathrm{~K}$ : (a) $\varepsilon=0.07$, (b,c) $\varepsilon=0.16$, (d) $\varepsilon=0.1+0.13$ (additional straining after re-polishing). 
dominant on opposite sides of crystals. At the central parts of the specimen the dominant system was not revealed.

With increasing strain, the features of simultaneous slip on two pairs of orthogonal slip systems were revealed. The well-defined traces of the third or the third and fourth slip planes belonging to (110) family were observed on both "edge" and "screw" surfaces of specimens at the end of stage II/onset of stage III (Fig. 2b,c). As it is evident in Fig. 2c, the additional slip along an oblique (110) plane is involved into general deformation process at these strains. The coarse traces of this slip system shear the earlier formed horizontal slip lines toward the slip direction, resulting in a characteristic wavy surface relief. This implies that slip becomes more heterogeneous on the mesoscale level and can be related to the development of shear bands. Generally, it can also be concluded that the strong interaction between dislocations belonging to various slip systems takes place.

At the strains corresponding to end of stage III/onset of stage IV the long slip bands with a width of about 30$50 \mu \mathrm{m}$ were observed in central parts of specimens (Fig. $2 \mathrm{~d})$. These bands were roughly parallel to $<210>$ direction and composed by slip lines belonging to two orthogonal systems of $\{110\}<110\rangle$. Inside each band the slip occurred separately. The multiple changes in slip direction from one slip system to another took place when the slip line arrived at the boundary of band. In comparison with the body of bands, the band boundaries, which are revealed as long strait bands with width of about 5-10 $\mu \mathrm{m}$, did not contain slip lines. In neighboring slip bands the slip lines of equivalent systems were misoriented on an angle of about $3-5^{\circ}$. But no progressive accumulation of misorientations was observed in transition across several bands.

3.3 Microstructure evolution. The microstructure developed in $\mathrm{LiF}$ single crystals in the earlier stages of deformation was quite similar to that in $\mathrm{NaCl}$ deformed by compression at ambient to intermediate temperatures $[9,12]$. So, the typical microstructures formed in stage III consist of areas of uniformly distributed dislocations interspersed with light patches of lower etch pit densities and long subboundaries oriented approximately in the $<100>$ direction.

In the current work the main attention was paid to the structural changes in the later stages of deformation. In stage IV the bands composed by etch pit and bounded by thick high density dislocation walls (or by pair of more thin walls) are revealed in the structure (Fig. 3a). These structural bands are roughly oriented along $<210>$ direction. Their width and their boundary width are approximately the same as those of slip bands described in the item 3.2. Further deformation
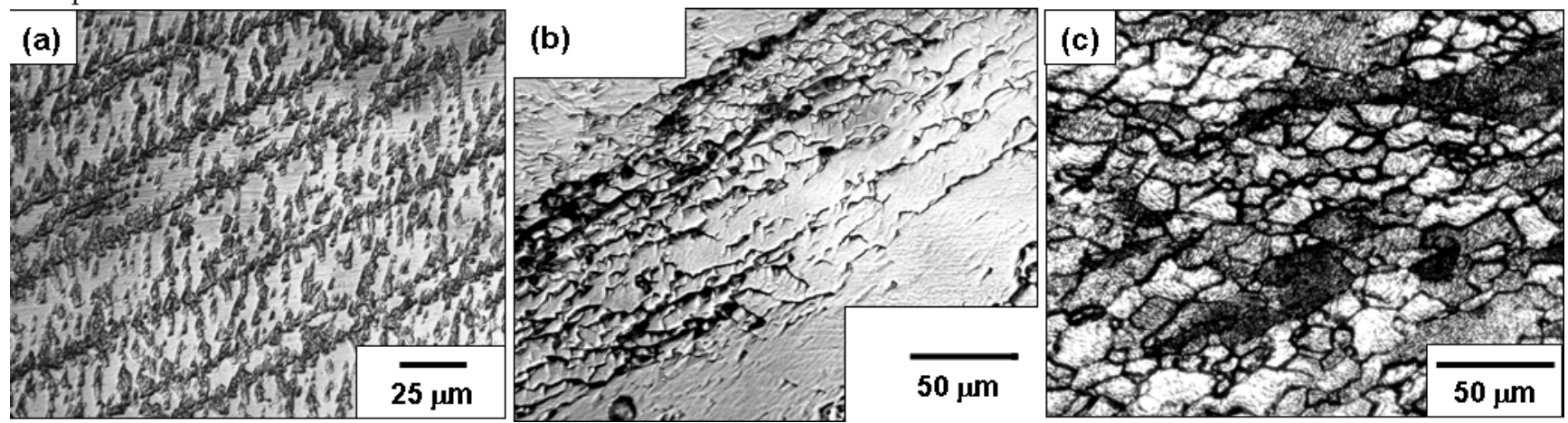

Fig. 3 Microstructure of LiF deformed at $\mathrm{T}=673 \mathrm{~K}$ : (a) $\varepsilon=0.3$, (b) $\varepsilon=0.5$, (c) $\varepsilon=1.05+0.1$ (additional straining after polishing/etching). leads to appearance of (sub)grain structure in the place of bands (Fig. 3b). Etching reveals both the long thick low-angle boundaries consisted of etch pits and more thin fragments that obviously are the high angled ones. The orientation of these long boundaries roughly corresponds to that of former bands. Concurrently shorter longitudinal and transverse boundaries are formed inside the bands. This provides the formation of (sub)grains with preferred rectangular shape and transverse size of about 10-20 $\mu \mathrm{m}$. Further deformation results in development of more equiaxed crystallites within the bands. Their volume fraction is gradually increased with increasing strain. A structure consisting of equiaxed grains is evolved after strains of beyond 1.4 (Fig. 3c). The grain size is ranging from 10 to $15 \mu \mathrm{m}$. The volume fraction of the recrystallized structure formed is about $60 \%$.

3.4 X-ray analysis. Data from the photo method support the results of microstructural observations. At the end of stage I/ onset of stage II the diffraction spots in the Debye shear patterns become diffused; that is indicative of bending of the crystal lattice upon upsetting. With further straining in stages III and IV, the diffraction patterns exhibit spots non-uniformly arranged within segments, which reflect lowangle misorientation of the developed (sub)grain structure. The typical pattern at strain of about 0.25 is represented in Fig. 4 a. It is seen that the diffraction spots are highly diffuse and form segments of rings specifically oriented with respect to $<100>$-direction in the crystal, reflecting, probably, the preferred orientation of deformation-induced subboundaries. At higher strains $(\varepsilon \geq 0.5)$ the spots tend to form whole rings; that are typical of deformation polycrystals (Fig. 4b).

\section{Discussion}

The results show that CDRX occurs in LiF single crystals during plastic deformation at $673 \mathrm{~K}$. Namely, it was found that the low angle boundaries are developed in material in the earlier stages of plastic deformation and some of them eventually convert into high angle ones at higher strains $[2,6,13]$. Such microstructural behavior of LiF single crystals may be in a contrast to that at higher temperatures( $T \geq 773$ $\mathrm{K})$, when an extensive migration of deformation-induced subboundaries created in initial stage of plastic flow resulted in their annihilation [14-16]. Since the most of intergranular interfaces evolved in material were swept by migrating subboundaries, this process was the main restoration mechanism that played a major role in the establishment of steady state of plastic flow [15]. 


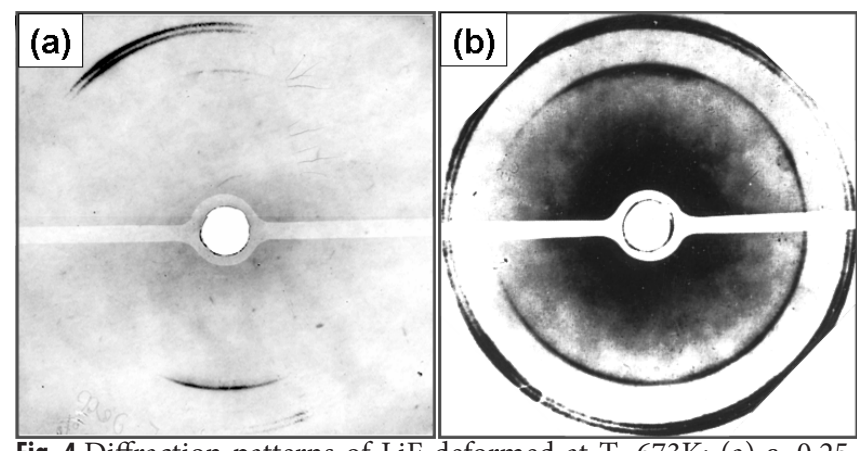

Fig. 4 Diffraction patterns of LiF deformed at $\mathrm{T}=673 \mathrm{~K}$ : (a) $\varepsilon=0.25$, (b) $\varepsilon=0.7$.

It has been shown in [14] that the boundaries evolved in the structure at $\mathrm{T}=773$ and $923 \mathrm{~K}$ constituted of the simple tilt dislocation walls of opposite signs. Those were formed during hot deformation in the power-law regime [10,11] due to localized slip on one preferred system [10] and dislocation rearrangement by dislocation climb. These boundaries were very feasible for migration and subsequent collision during deformation [14,15]. The velocity of their migration was found to be rather high and increased with increasing temperature; that hindered CDRX, i.e. recrystallization behavior of $\langle 100\rangle$ - oriented LiF single crystals was found strongly depended on deformation temperature.

At the same time, the occurrence of CDRX at $673 \mathrm{~K}$ cannot be explained only by the temperature effect on the rate of subgrain boundary migration [15]. Besides, it is also caused by the character of (sub)structural evolution, which differs substantially from that at higher temperatures [14-16]. The data in Fig. 2 suggest that dislocation walls formed in $\mathrm{LiF}$ at $673 \mathrm{~K}$ are the main prerequisite for development of a stable (sub)grain structure that provides CDRX occurrence. The distinctive features of subboundaries developed at $673 \mathrm{~K}$ are caused by the fact, that they are sufficiently immobile. Let us discuss how these features are connected with peculiarities of dislocation glide and cause formation of new grains.

4.1 Shape of $\sigma-\varepsilon$ curve and slip systems. In contrast to fcc metals, which normally exhibit three stages of workhardening at low-to-moderate strains [8], four stages of plastic flow were detected in stress-strain curves of LiF single crystals at $673 \mathrm{~K}$ and stage IV was the most prolonged (Fig. 1 ). This difference is most likely arisen from the peculiarities of dislocation properties and glide conditions in ionic crystal at temperatures of $0.4-0.7 \mathrm{~T}_{\mathrm{m}}$ [7]. Note, that four stages in $\sigma-\varepsilon$ curves in this temperature interval were earlier reported for $\mathrm{MgO}$ and LiF single crystals, deformed by both compression and tension [7]. The existence of stage IV can be explained by successive glide in four $\{110\}<110>$ equivalent slip systems [7]. The present data on dislocation structure and slip features in stages III and IV in LiF single crystal confirms indirectly this suggestion [7,12]. According to [17], if four slip systems are concurrently operative in a simple ionic crystal, a reaction between dislocations capable of gliding on $\{110\}$ planes and having Burgers vector $1 / 2 \mathrm{a}<110>$ :

$$
1 / 2 \mathrm{a}[101]+1 / 2 \mathrm{a}[011]->1 / 2 \mathrm{a}[110]
$$

is favored. The new dislocation with Burgers vector $1 / 2 \mathrm{a}[110]$ should be capable of gliding on the (112) plane (see Fig. 2), since this plane contains both its line and its Burgers vector. Since (112) is not a normal slip plane for ionic crystals, however, the new dislocations will be relatively immobile [17]. Obliviously, the appearance of these low-mobile dislocations in LiF crystals at $673 \mathrm{~K}$ takes place in stage III when third and fourth $\{110\}<110>$ slip systems begin to operate (Fig. 2b). Their accumulation in $\{112\}$ planes results in formation of dislocation walls, which subdivide the deformed crystal into several bands. These dislocation walls (revealed to be parallel to a $<210>$ direction in a $\{100\}$ plain) act as obstacles for the dislocations of the major slip systems. Accordingly slip becomes localized on the narrow regions between dislocation walls. As a result the separate slip bands bonded by dislocation walls are formed leading to a strong localization of plastic flow on the mesoscopic level. Note that the specific multiple slip caused by multiple changes in slip direction of edge dislocations from one $<110>\{110\}$ slip system to another is operative inside these bands. In accordance with dislocation reactions [17] this leads to appearance of orientation misfit dislocations in the vicinities of slip band boundaries. The transition to stage IV (i.e. stage of higher work hardening) occurs likely due to formation of structural bands and enhancement of dislocation density in them. The lattice dislocations get held up at the band boundaries. As a result the regions adjacent to dislocation walls are saturated by dislocations of various signs causing the enhanced elastic strains in slip bands [12].

4.2 CDRX. As mentioned above, dislocation subboundaries frequently develop in the earlier stages of deformation in the deformed $\mathrm{LiF}$ crystals due to some mechanically induced events. Hence, these boundaries may be rather non-equilibrium and diffuse interfaces (see Fig. 3a). Dynamic recovery that occurs with high rate at elevated temperature can assist the transformation of such straininduced non-equilibrium boundaries to more equilibrium ones, leading to rapid occurrence of CDRX [13]. Inspection of the data $[10,11]$ represented for $<100>$-oriented LiF single crystals allows concluding that $673 \mathrm{~K}$ is a warm deformation temperature, in vicinity of which a "power-law breakdown" takes place. Accordingly a low-temperature dislocation climb on short-range distances can control the deformation process $[10,18]$. Dislocations can be rearranged by climb inside dislocation walls during deformation. This intrinsic dislocation rearrangement in conjunction with persistent accumulation of lattice dislocations in dislocation walls causes the fast transformation of these walls into more equilibrium and flat (sub)grain boundaries [12,19]. Concurrently, the transverse low-angle boundaries begin to form inside the bands. This process probably occurs due to rearrangements of dislocations on longer-range distance by climb and hence the rate of formation of transverse boundaries is lower than that of longitudinal boundaries. The transverse subboundaries may also be formed by a crystal subdivision process as a result of microshear banding (Fig. 2c) that is caused by intrinsic structure instability during deformation $[13,19]$.

Note that the longitudinal boundaries formed in the place of dislocation walls remain essentially stable, since they are composed mainly of low-mobile dislocations [17]. As a result, stabilized arrays of (sub)grain boundaries are formed in the place of bands. The new crystallites have a nonequilibrium elongated rectangular shape that is typical for the 
dominant dislocation slip on two orthogonal slip systems [3] At further deformation a progressive increase in boundary misorientation takes place (Fig. 4), which is attributed to trap of gliding dislocations by low-angled boundaries. As a result the latter gradually converse into higher angle ones [6]. Recrystallized grains form in the site of former elongated subgrains and inherit their shape. This configuration of highangle boundaries is of non-equilibrium type and subsequent grain boundary migration provides the formation of an equilibrium network of high-angle boundaries [19] in the site of prior band structures.

\section{Conclusions}

1. Plastic deformation of the $<100>$ oriented LiF single crystals at an intermediate temperature $(673 \mathrm{~K})$ results in formation of new grain structure. New grains with size ranging from 10 to $15 \mu \mathrm{m}$ are developed at strains of beyond 1 due to occurrence of CDRX.

2. Localization of plastic deformation providing development of stable band-like substructures after relatively small strains plays an important role in CDRX. Longitudinal boundaries of such bands have low migrating ability; that prevents collision and further mutual annihilation of subboundaries of opposite signs. As a result, stable arrays of low-angle boundaries are formed.

3. Further straining, leading to continuous increase in misorientation of subboundaries and their eventual conversion into high angle boundaries, results in the formation of recrystallized grains.

\section{References}

1. S.J. Hales, T.R. McNelley, Acta Metall., 36, 1229 (1988)

2. F.J. Humphreys, M. Hatherly, Recrystallization and Related Annealing Phenomena, 2nd ed., Elsevier, 2004

3. M. Guillope, J.-P. Poirier, J. Geophys. Res., 84, 5557 (1979)

4. C. Perdrix, M.Y. Perrin, F. Montheillet, Mem. Sci. Rev. Metall., 78, 309 (1981)

5. X. Yang, H. Miura, T. Sakai, Mater. Trans., 44, 197 (2003)

6. S. Gourdet, F. Montheillet, Mater. Sci. Eng., A238, 274 (2000)

7. N.Skvortzova, G. Berezhkova, Cryst. Res. Technol, 21, 939 (1986)

8. R. Honeycombe "The Plastic Deformation of Metals", Arnold Ltd, 1968

9. S.V. Raj, G.M. Pharr, Mater. Sci. Eng., A122, 233 (1989)

10. N. Skvortsova, Cryst. Res. Technol, 31, 373 (1996)

11. M. Biberger, W. Blum, Scripta Met., 23, 1419 (1989)

12. R.W. Davidge, P.L. Pratt, Phys. Stat. Sol., 6, 759 (1964)

13. O. Sitdikov, T. Sakai, A. Goloborodko, H. Miura, R. Kaibyshev, Phil. Mag., 1159, 85 (2005)

14. M. Biberger, W. Blum, Phil. Mag. A, 65, 757 (1992)

15. M. Biberger, W. Blum, Phil. Mag. A, 66, 27 (1992)

16. W. Muller, M. Biberger, W. Blum, Phil. Mag. A, 66, 717 (1992)

17. B.H. Kear, A. Taylor, P.L. Pratt, Phil. Mag. A., 6, 665 (1959)

18. J. Chadek "Creep in Metallic Materials", Academia, 1984

19. I. Mazurina, T. Sakai, H. Miura, O. Sitdikov, R. Kaibyshev, Mater. Trans., 50, 101 (2009) 